\title{
Impact of changes in television viewing time and physical activity on longevity: a prospective cohort study
}

\author{
Sarah Kozey Keadle ${ }^{1,2^{*}}$, Hannah Arem¹, Steven C. Moore ${ }^{1}$, Joshua N. Sampson ${ }^{3}$ and Charles E. Matthews ${ }^{1}$
}

\begin{abstract}
Background: Television viewing is a highly prevalent sedentary behavior among older adults, yet the mortality risks associated with hours of daily viewing over many years and whether increasing or decreasing viewing time affects mortality is unclear. This study examined: 1) the long-term association between mortality and daily viewing time; 2) the influence of reducing and increasing in television viewing time on longevity and 3) combined effects of television viewing and moderate-to-vigorous physical activity (MVPA) on longevity.
\end{abstract}

Methods: Participants included 165,087 adults in the NIH-AARP Diet and Health (aged 50-71 yrs) who completed questionnaires at two-time-points (Time 1: 1994-1996, and Time 2: 2004-2006) and were followed until death or December 31, 2011. Multivariable-adjusted Cox proportional hazards regression was used to estimate Hazard Ratios and $95 \%$ confidence intervals $(\mathrm{Cl})$ with self-reported television viewing and MVPA and all-cause mortality.

Results: Over 6.6 years of follow-up, there were 20,104 deaths. Compared to adults who watched $<3 \mathrm{~h} /$ day of television at both time points, mortality risk was $28 \%$ greater $(\mathrm{Cl}: 1.21,1.34)$ those who watched $5+$ h/day at both time-points. Decreasing television viewing from $5+\mathrm{h} /$ day to $3-4 \mathrm{~h} / \mathrm{d}$ was associated with a $15 \%$ reduction in mortality risk $(\mathrm{Cl}: 0.80,0.91)$ and decreasing to $<3 \mathrm{~h} /$ day resulted in an $12 \%$ lower risk $(\mathrm{Cl}: 0.79,0.97)$. Conversely, adults who increased their viewing time to $3-4 \mathrm{~h} /$ day had an $17 \%$ greater mortality risk (Cl:1.10, 1.24) and those who increased to $5+\mathrm{h} /$ day had a $45 \%$ greater risk $(\mathrm{Cl}: 1.32,1.58)$, compared to those who consistently watched $<3 \mathrm{~h} /$ day. The lowest mortality risk was observed in those who were consistently active and watched $<3 \mathrm{~h} /$ day of television.

Conclusions: We confirm that prolonged television viewing time was associated with greater mortality in older adults and demonstrate for the first time that individuals who reduced the amount of time they spent watching television had lower mortality. Our findings provide new evidence to support behavioral interventions that seek to reduce sedentary television viewing in favor of more physically active pursuits, preferably MVPA. Given the high prevalence of physical inactivity and prolonged television viewing in older adults, favorable changes in these two modifiable behaviors could have substantial public health impact.

Trial registration: ClinicalTrials.gov number, NCT00340015

Keywords: Sedentary behavior, Television, Mortality, Prospective cohort

\footnotetext{
* Correspondence: sarah.keadle@nih.gov

${ }^{1}$ Nutritional Epidemiology Branch, Division of Cancer Epidemiology and

Genetics, National Cancer Institute, Bethesda, MD, USA

${ }^{2}$ Cancer Prevention Fellowship Program, Division of Cancer Prevention,

National Cancer Institute, Bethesda, MD, USA

Full list of author information is available at the end of the article
}

(C) 2015 Keadle et al. Open Access This article is distributed under the terms of the Creative Commons Attribution 4.0 International License (http://creativecommons.org/licenses/by/4.0/), which permits unrestricted use, distribution, and reproduction in any medium, provided you give appropriate credit to the original author(s) and the source, provide a link to the Creative Commons license, and indicate if changes were made. The Creative Commons Public Domain Dedication waiver (http://creativecommons.org/publicdomain/zero/1.0/) applies to the data made available in this article, unless otherwise stated. 


\section{Background}

The number of older adults ( $\geq 65 \mathrm{yrs})$ in the United States (US) is projected to increase from 40 million to 72 million over the next two decades [1], and individuals who reach age 65 are expected to live an additional 19 years [2]. Engaging in moderate-to-vigorous physical activity (MVPA) is an established component of healthy aging and initiating MVPA later in life can improve health and longevity [3-5]. However, older adults spend the majority of their waking day in sedentary behavior (i.e., sitting) [6]. Sedentary television viewing the most prevalent leisure-time sedentary behavior [7, 8], and on a given day nearly $90 \%$ of older US adults watch television, for an average of $4.7 \mathrm{~h}$ per day [9]. Several studies have reported that television viewing is associated with increased risk of mortality, including 8 of the leading causes of death in the United States [10-17]. The discretionary nature, high prevalence and previously identified mortality risks from prolonged television viewing suggest reducing this behavior may have substantial public health impact, but key aspects of the television/mortality relationship remain poorly understood.

To date, prospective mortality studies have only measured television viewing at single point in time, and the magnitude of the risk estimates derived from these studies may be underestimated due to regression dilution bias [18]. Additionally, the impact of reducing or increasing time spent watching television and risk of mortality is not currently known. Such knowledge would help to estimate the effects of an intervention designed to decrease television viewing. Given the scarcity of randomized trials targeting television viewing and MVPA with mortality end-points, prospective studies with exposures measured at multiple time-points form a natural experiment that yield essential insights into the impact of changes in behavior on mortality risk. Accordingly, the purpose of this investigation, conducted within a large prospective study is to: 1) estimate the mortality risk associated with many years of prolonged television viewing, and 2) Evaluate the influence of changes in television viewing time on mortality risk. We also describe associations for MVPA over time and explore the independent and combined effects of changes in both television viewing and MVPA on longevity.

\section{Methods}

\section{Cohort information and informed consent}

The NIH-AARP Diet and Health Study is a prospective cohort that was established in 1995-96 when 566,398 AARP members (aged 50-71 years) who lived in one of six states (California, Florida, Louisiana, New Jersey, North Carolina, and Pennsylvania) or two metropolitan areas (Atlanta, Georgia, and Detroit, Michigan) responded to a questionnaire about their medical history, diet, and demographics (ClinicalTrials.gov number, NCT00340015) [19]. Within six months, those without colon, breast or prostate cancer were mailed a Risk Factor Questionnaire that asked about sedentary behaviors and physical activity ( $n=334,908)$. In 2004-2006, all participants were mailed a Follow-up Questionnaire that asked detailed questions about active and sedentary behaviors, and other risk factors $(n=313,835)$. Completion of the questionnaires was considered to imply informed consent. The Special Studies Institutional Review Board of the US National Cancer Institute approved the study.

\section{Analytic study design and End point ascertainment}

There were 221,189 individuals who returned both the Risk Factor (Time 1) and Follow-up Questionnaire (Time 2) making them eligible for this analysis (Fig. 1). Of these, we excluded proxy respondents $(n=15,602)$ and those missing physical activity and television data $(n=22,785)$. To minimize reverse causality we also excluded those who had poor self-reported health at Time 1 or Time $2(n=5137)$ or who had missing data for this variable $(n=12,137)$. The final sample included 165,087 individuals. Cohort members were followed by linkage to the US Postal Service National Change of Address database, through processing of undeliverable mail, address change services, and direct contact. Vital status was determined through linkage with the Social Security Administration Death Master File [20], and the National Death Index [21]. The primary end point was all-cause mortality. Verification of vital status was available for $>95 \%$ of the cohort.

\section{Assessment of television viewing and MVPA}

A detailed description of our estimates of television viewing and MVPA are provided in our supplementary materials (Additional file 1). Briefly, we harmonized the self-reported television and MVPA responses into the most meaningful categories allowed by both measures and that ensured adequate cell sizes for change analyses. The categories were $<3,3-4$, and $5+$ hours per day (h/day) for television viewing and $<1,1-4$, and $4+$ hours per week (h/wk) for MVPA participation.

Studies reporting the reliability of television viewing questionnaires indicate moderate to high reliability (ICC $=0.78-0.93)[22-24]$ and are similar in general adults, unemployed and retired individuals (ICC = 0.76-0.93) [25]. Gardiner and colleagues showed reported sedentary behaviors were as responsive to change as the ActiGraph 100 count cut-point method to estimate sedentary time [22]. Criterion validity of these particular television viewing questions has not been evaluated, but the questions are similar to questions that have acceptable validity compared to behavioral logs $\left(r^{2}=0.61\right)[26]$ and an electronic TV monitor $\left(r^{2}=0.51\right)$ 


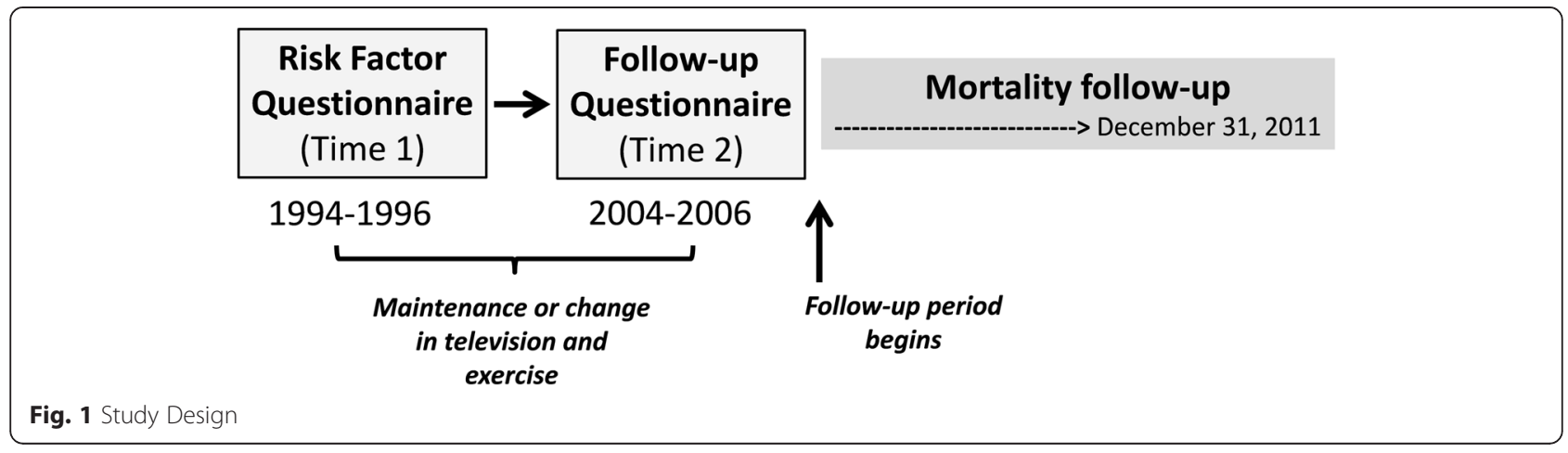

[27]. The MVPA questions used at Time 2 are nearly identical to questions that have been validated against physical activity diaries, $\mathrm{R}=0.62$ and 0.65 , in the Harvard Cohorts [28, 29].

\section{Covariates}

To identify potential confounders we examined each of the self-reported factors listed in Table 1 in age (yrs) and gender (male or female), adjusted models of change in TV time and mortality and retained only those demonstrating evidence of confounding (>5\% change). These factors were education $(<12$ yrs, high school graduate, some college, college graduate, or missing), smoking history (never; quit, <20 cigarettes/d; quit, >20 cigarettes/d; current, <20 cigarettes/d; current, 20 cigarettes/d; or unknown), history of heart disease (yes/no), other chronic conditions (yes/no), health status (fair, good, very good or excellent), and change in BMI categories between Time 1 and Time $2(<25,25-30$, $>30 \mathrm{~kg} / \mathrm{m}^{2}$ ). Extreme BMI values (i.e., $<15$ or $>60 \mathrm{~kg} / \mathrm{m}^{2}$ ) were set as missing. Due to know differences in levels of these exposures by television viewing patterns, we

Table 1 Participant characteristics by television viewing and MVPA participation at Time 2*: the NIH-AARP Diet and Health Study

\begin{tabular}{|c|c|c|c|c|c|c|}
\hline & \multicolumn{3}{|c|}{ Television viewing (h/day) } & \multicolumn{3}{|c|}{ MVPA (h/wk) } \\
\hline & $<3$ & $3-4$ & $5+$ & $<1$ & $1-4$ & $4+$ \\
\hline N & 70963 & 59162 & 35062 & 38058 & 53237 & 72951 \\
\hline Age $(y)$ & $70.1(5.4)$ & $71.0(5.2)$ & $71.3(5.1)$ & $70.7(5.4)$ & $70.8(5.3)$ & $70.6(5.2)$ \\
\hline BMI $\left(\mathrm{kg} / \mathrm{m}^{2}\right)$ & $26.1(4.2)$ & $27.0(4.5)$ & $28.0(5.2)$ & $28.0(5.3)$ & $26.9(4.6)$ & $26.1(4.0)$ \\
\hline Education-some college (\%) & 74.8 & 65.1 & 57.4 & 58.8 & 65.9 & 73.6 \\
\hline Married (\%) & 71.2 & 69.9 & 63.7 & 64.5 & 66.9 & 73.1 \\
\hline Race (\% white) & 94.1 & 93.9 & 92.0 & 92.5 & 93.5 & 94.2 \\
\hline Very good/excellent health (\%) & 60.8 & 49.3 & 39.7 & 38.4 & 48.2 & 62.3 \\
\hline Retired (\%) & 70.5 & 81.8 & 86.9 & 75.1 & 76.8 & 80.5 \\
\hline Sleep <7 h/night (\%) & 26.9 & 27.9 & 29.1 & 31.3 & 28.0 & 25.7 \\
\hline MVPA 4+ h/wk (\%) & 46.2 & 35.5 & 18.3 & - & - & - \\
\hline Television 5+ h/day (\%) & - & - & - & 27.4 & 20.8 & 18.3 \\
\hline \multicolumn{7}{|l|}{ Ever diagnosed with (\%): } \\
\hline Coronary heart disease & 18.1 & 22.7 & 25.6 & 22.4 & 21.2 & 21.0 \\
\hline Cancer & 12.8 & 13.6 & 14.1 & 13.7 & 13.3 & 13.3 \\
\hline Chronic condition & 6.0 & 8.1 & 11.2 & 11.1 & 8.2 & 6.0 \\
\hline Degenerative disease & 0.7 & 1.0 & 1.2 & 1.3 & 1.0 & 0.7 \\
\hline Depression & 11.6 & 12.2 & 15.4 & 16.1 & 13.7 & 10.1 \\
\hline Hypertension & 48.8 & 55.7 & 60.5 & 57.7 & 55.5 & 50.4 \\
\hline High Cholesterol & 52.0 & 57.5 & 59.6 & 55.4 & 56.3 & 55.2 \\
\hline Diabetes & 11.3 & 15.5 & 20.3 & 18.6 & 15.5 & 12.1 \\
\hline
\end{tabular}

Information at Time 2 was reported on the Follow-up Questionnaire, administered 2004-2006. Values in parentheses are standard deviation. Degenerative diseases refer to Parkinson's Diease, Amyotrophic lateral sclerosis or Multiple Sclerosis 
also adjusted for race (white, black, other, or missing) and depression (self-reported physician diagnosed depression [yes, no, or missing]). Missing values were included as covariates and were less than $8 \%$ for all included variables. Mutual adjustment for MVPA and $\mathrm{TV}$ viewing duration was also completed, as necessary. For covariates that could have changed between Time 1 and Time 2 we used the values reported at Time 2.

\section{Statistical analyses}

Cox proportional hazards regression models were used to obtain adjusted hazard ratios (HR) and $95 \%$ confidence intervals $(\mathrm{CI})$. Follow-up time was calculated from the Time 2 questionnaire until death or December 31, 2011 (Fig. 1). First we estimated the HR and 95 \% CI for television viewing at each time point. To evaluate the long-term risks associated with television viewing we then estimated HRs for those who reported maintaining the same amount of television viewing at Time 1 and 2 (i.e., no change). To estimate associations for increasing or decreasing television viewing, we fit models stratified by television viewing at Time 1 , using those who maintained the same television viewing time at both timepoints as the reference group. Parallel analyses were completed for MVPA participation. Sensitivity analyses were conducted for our main analysis to evaluate potential reverse causality by excluding the first year of follow up and excluding individuals with cardiovascular disease, cancer, renal disease or neurodegenerative conditions (i.e., Parkinson's Disease, Amyotrophic lateral sclerosis or Multiple Sclerosis). We also compared the HR's for change in television and MVPA in men and women separately, by BMI status $\left(<25 \mathrm{~kg} / \mathrm{m}^{2}\right.$ vs. $\left.\geq 25 \mathrm{~kg} / \mathrm{m}^{2}\right)$ and in younger and older individuals based on median age at Time 2.

We examined the joint effects of changes in both television and MVPA. To preserve power for this analysis we evaluated only two categories for television viewing $(<3$ and $3+\mathrm{h} /$ day $)$ and MVPA participation $(<1$ and $1+$ $\mathrm{h} / \mathrm{wk}$ ) and set the highest risk group (i.e., those reporting high levels of television ( $3+\mathrm{h} /$ day) and low levels of MVPA ( $<1 \mathrm{~h} / \mathrm{wk})$ at both time-points) as referent. Spearman correlations were assessed for our measures of television and MVPA over time.

We tested for violations of the proportional hazards assumption in our primary analyses by comparing, using the likelihood ratio test, models with and without the log (time) by exposure group interactions [30]. Given evidence of minor violations for some of the models tested, we pursued secondary analyses where we allowed the effect of each exposure category to change at followup time of three years. The risk estimates for those who died within the first 3 years of follow-up $(N=6587)$ were slightly stronger than deaths occurring after 3 yrs $(13,517)$ (Additional file 1: Tables S1-S2). However, the direction the associations for all of the models were consistent over time and did not warrant further stratification of results by follow-up time. SAS 9.3 was used for all analysis and statistical significance was set at $P<0.05$.

\section{Results}

Over 6.6 years of follow-up, there were 20,104 deaths. Participant characteristics at Time 2 are presented in Table 1. Those who watched more television and engaged in less MVPA tended to be less educated, less likely to report excellent or very good health and more likely to be retired and have received diagnoses of hypertension or depression. Those who watched more television also had higher rates of coronary heart disease, diabetes and high cholesterol. Additional file 1: Tables S3-S4 show the participant characteristics across the 9-change categories for television viewing and MVPA, respectively.

First we evaluated the risks associated with television viewing and MVPA in separate models for Times 1 and 2 (Table 2). Mortality was greater for prolonged television viewing at both time points after adjusting for demographic factors, smoking, body mass index, selfreported health, pre-existing disease and MVPA participation (Table 2). The mortality risk increased at both Time 1 (HR [95\% CI]) $(1.11[1.06,1.15])$ and Time 2 $(1.29[1.25,1.34])$ for those who watched $5+$ vs. $<3 \mathrm{~h} /$ day. Engaging in MVPA $(<1 \mathrm{~h} / \mathrm{wk}$ vs $>4 \mathrm{~h} / \mathrm{wk})$ was associated with decreased mortality risk at both time-points (Time 1: 0.98 [0.86-0.92] and Time 2: 0.69 [0.66-0.71]) (Table 2). The Spearman correlations television viewing and MVPA participation between Time 1 and Time 2 were $R=0.53$ and $R=0.31$, respectively. In the Time 2 questions, we examined the proportion of MVPA that came from different types of activity and found most of the reported MVPA came from walking (54 \%) and $12 \%$ was reported as vigorous activity.

To estimate the mortality risk associated with many years of prolonged television viewing and MVPA participation, we evaluated those who maintained the same level of each behavior at both time-points (Fig. 2, Panel a). Compared to those who watched $<3 \mathrm{~h} /$ day at both time-points, mortality risk was higher for individuals who consistently watched $3-4 \mathrm{~h} /$ day $(1.13[1.08,1.18])$ and for those who consistently watched $5+\mathrm{h} /$ day $(1.28[1.22,1.35])$. Those who maintained $>4 \mathrm{~h} / \mathrm{wk}$ of MVPA over time were at a $33 \%$ lower risk $(0.67[0.64,0.70])$ compared to those reporting $<1 \mathrm{~h} / \mathrm{wk}$ of MVPA at both time points (Fig. 2, Panel b). Results for both television viewing and MVPA were similar for women and men. 
Table 2 Associations (HR [95 \% Cl]) between television viewing and MVPA participation and mortality at Time 1 and Time 2, the $\mathrm{NIH}-\mathrm{AARP}$ Diet and Health Study

\begin{tabular}{|c|c|c|c|c|c|c|c|c|}
\hline \multirow{2}{*}{ Television viewing } & \multicolumn{4}{|c|}{ Time 1 (1996-1997) } & \multicolumn{4}{|c|}{ Time 2 (2004-2006) } \\
\hline & & & & & & & & \\
\hline & $<3$ h/day & 3-4 h/day & $5+$ h/day & $p$-value & $<3$ h/day & 3-4 h/day & $5+$ h/day & p-value \\
\hline N (deaths) & $56385(6061)$ & $63278(9191)$ & $25420(4852)$ & & $64275(6688)$ & $51615(7547)$ & $29193(5869)$ & \\
\hline Age and sex & 1.0 (Referent) & $1.21(1.17,1.25)$ & $1.53(1.47,1.59)$ & $<0.001$ & 1.0 (Referent) & $1.28(1.24,1.32)$ & $1.71(1.65,1.77)$ & $<0.001$ \\
\hline Fully-adjusted model & 1.0 (Referent) & $1.04(1.01,1.08)$ & $1.11(1.06,1.15)$ & $<0.001$ & 1.0 (Referent) & $1.11(1.08,1.15)$ & $1.29(1.25,1.34)$ & $<0.001$ \\
\hline \multicolumn{9}{|c|}{ Moderate-to-vigorous physical activity } \\
\hline & $<1 \mathrm{~h} / \mathrm{wk}$ & $1-4 \mathrm{~h} / \mathrm{wk}$ & $>4 \mathrm{~h} / \mathrm{wk}$ & & $<1 \mathrm{~h} / \mathrm{wk}$ & $1-4 \mathrm{~h} / \mathrm{wk}$ & $>4 \mathrm{~h} / \mathrm{wk}$ & \\
\hline N (deaths) & $32182(6061)$ & $37208(5058)$ & $75693(9543)$ & & $31622(6436)$ & $47430(6748)$ & $66031(6920)$ & \\
\hline Age and sex & 1.0 (Referent) & $0.80(0.77,0.83)$ & $0.70(0.67,0.72)$ & $<0.001$ & 1.0 (Referent) & $0.70(0.68,0.72)$ & $0.51(0.49,0.53)$ & $<0.001$ \\
\hline Fully-adjusted model & 1.0 (Referent) & $0.92(0.89,0.96)$ & $0.89(0.86,0.92)$ & $<0.001$ & 1.0 (Referent) & $0.82(0.79,0.85)$ & $0.69(0.66,0.71)$ & $<0.001$ \\
\hline
\end{tabular}

\section{Changes in television viewing and MVPA participation}

Among those with higher levels of television viewing at baseline, individuals who reduced their amount of television viewing over time had significantly lower mortality compared to those who maintained the same level of viewing (Fig. 3, Panel a). Mortality risk was $15 \%$ lower in adults who reduced their viewing from $5+\mathrm{h} /$ day at Time 1 to $3-4 \mathrm{~h} /$ day at Time 2 $(0.85[0.80,0.91])$, and $12 \%$ lower for those who reduced to $<3 \mathrm{~h}$ /day at Time $2(0.88[0.79,0.97])$, compared to those who consistently watched $5+\mathrm{h} /$ day. Conversely, those who increased television viewing at Time 1 from $<3 \mathrm{~h}$ /day to3-4 h/day had an increased risk $(1.17[1.10,1.24])$ and those who increased to 5+ $\mathrm{h} /$ day had a greater risk $(1.45[1.32,1.58])$, compared to those who consistently watched $<3 \mathrm{~h} /$ day.

Reduction in MVPA was also associated with higher mortality and increased MVPA was associated with lower mortality (Fig. 3, Panel b). For example, mortality risk was lower among individuals who increased their reported MVPA from $<1 \mathrm{~h} / \mathrm{wk}$ at Time 1 to $1-4 \mathrm{~h} / \mathrm{wk}$ $(0.82[0.77,0.87])$ and those who increased MVPA from $<1 \mathrm{~h} /$ wk to $4+\mathrm{h} /$ day $(0.67[0.62,0.72])$, compared to those who reported $<1 \mathrm{~h} /$ wk of MVPA over time.

Results of the sensitivity analyses excluding the first year of follow-up and those with chronic conditions were similar to the overall values suggesting these factors did not exert a major impact on our results and minimizing reverse causation concerns (Table 3, Additional file 1: Table S5-S6). For example, for participants who decreased television viewing from $5+\mathrm{h}$ /day to $3-4 \mathrm{~h} /$ day, the overall estimate was $0.85(0.80,0.91)$ and once those with any history chronic conditions were excluded the estimate was 0.84 (0.76-0.93).
Similarly, the estimates for increasing from $3+\mathrm{h} /$ day to $4+\mathrm{h}$ /day were $1.45(1.32,1.58)$ for the overall sample and $1.41(1.22,1.62)$ for those without any chronic conditions. Risk estimates were also similar in normal weight compared to overweight/obese participants, and men and women (Table 3, Additional file 1: Table S6). The risks of television viewing appeared to be slightly stronger in younger individuals, indicated by a significant age group by television interaction $(P<0.05)$.

\section{Combined effects of maintenance and changes in television viewing and MVPA participation}

To estimate the risk associated with various combinations of maintenance and change in television viewing time and MVPA participation we compared each behavioral category to a high risk referent group (i.e., those reporting high levels of television $(3+\mathrm{h} /$ day) and low levels of MVPA ( $<1 \mathrm{~h} / \mathrm{wk})$ at both time-points); Table 4). Relative to the high-risk referent group, individuals who were active and watched little television at both timepoints had the lowest mortality risk (0.60 [0.56-0.64]). Compared to those who did low MVPA and watched high amounts of television, individuals who maintained low levels of MVPA but watched low levels of television at both time-points had a $20 \%$ reduction in risk $(0.80$ $[0.72,0.90])$, while those who maintained high levels of television but consistently engaged in MVPA had a $28 \%$ lower mortality risk $(0.72[0.68,0.76])$. Those who made positive changes in both behaviors (i.e., increased MVPA and decreased television viewing over time) had a $29 \%$ lower mortality risk $(0.71[0.63,0.79])$, compared to those who engaged in little MVPA and watched more television at both time-points. 


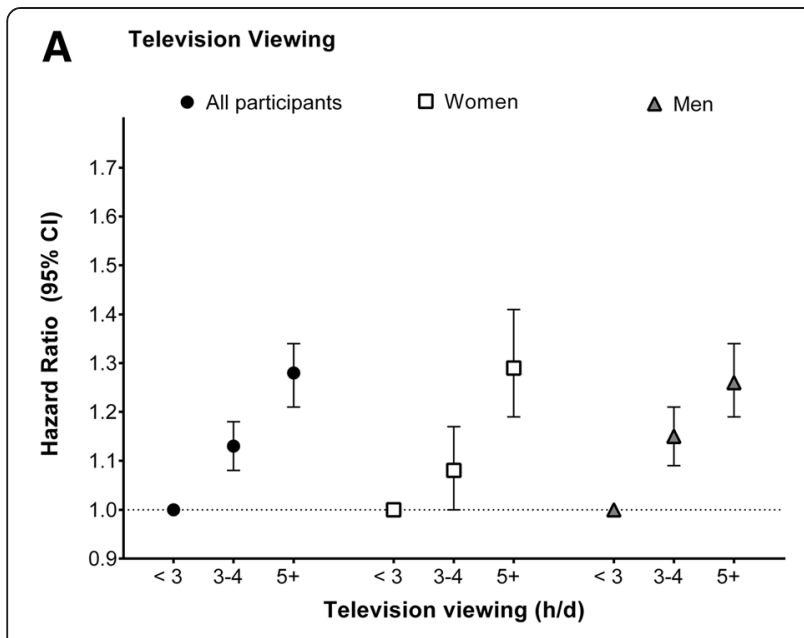

B Moderate-to-vigorous physical activity

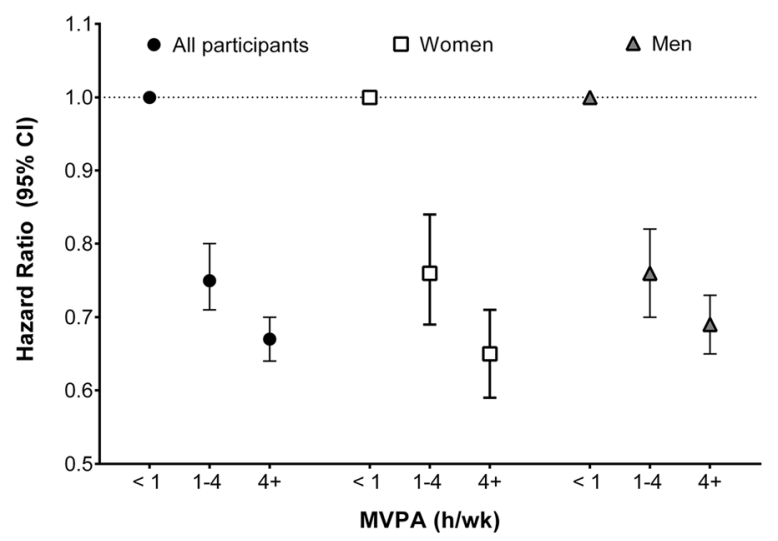

Fig. 2 Associations between long-term patterns of television viewing (Panel a) and MVPA participation (Panel b) on mortality, in all participants and by sex, the NIH-AARP Diet and Health Study.

* Participants in this analysis reported the same category of television viewing or MVPA at both Time 1 (1995-1996) and Time 2 (2004-2006). Fully adjusted model: age (yrs), sex (male or female), race (white, black, other, or missing), education ( $<12$ yrs, high school graduate, some college, college graduate, or missing), smoking history (never; quit, $<20$ cigarettes/d; quit, $>20$ cigarettes/d; current, $<20$ cigarettes/d; current, .20 cigarettes/d; or unknown), history of heart disease (yes/no), other chronic conditions (yes/no), depression (yes/no, missing), health status (fair, good, very good or excellent), and change in BMl category from Time 1 to Time $2(<25,25-<30,>30$, or missing), and MVPA or television viewing respectively

\section{Discussion}

In this large prospective study of older adults we confirm and extend previous research by quantifying the adverse impact on mortality for higher levels of television viewing over many years. We also report, for the first time, that older adults who increased their amount of viewing over time had higher mortality, and that individuals who chose to reduce the amount of time they spent watching television had significantly lower mortality. While previous studies have demonstrated that older adults who increase participation in MVPA have lower mortality $[3,4,31]$, until now it was unknown whether reductions in television viewing might also confer mortality benefits. Our findings suggest that reducing time spent in the most prevalent leisure time sedentary behavior in the US (television viewing) can improve health and longevity. Mortality benefits for increasing MVPA were robust and the greatest benefit was observed for those who watched little television and engaged in MVPA at least $1 \mathrm{~h} / \mathrm{wk}$. Given the high prevalence of physical inactivity and prolonged television viewing among older adults in the US and other western countries, favorable changes in these two modifiable behaviors could have a substantial clinical and public health impact.

Prior studies of television viewing and mortality evaluated excess risk at a single point in time [10-16] and these studies may have underestimated the true strength of this association due to regression dilution bias, or the failure to account for changes in behavior over time [17]. However, the risk estimate we observed for prolonged television viewing over many years, which relied on two measures of television viewing about 10 years apart, were largely consistent with the strength of association reported in earlier studies. A 2011 meta-analysis estimated a $13 \%$ increase in mortality risk per 2 -h of television viewing [13], while a 2015 meta-analysis showed a $22 \%$ increased mortality risk in the highest vs lowest category of sedentary time (including television), with $12 / 14$ prospective studies reporting positive associations [32]. In the present study, individuals who consistently watched television for $5+\mathrm{h}$ /day over many years had a $28 \%$ higher mortality risk than those who consistently watched $<3 \mathrm{~h} /$ day. This result has significant implications because the majority of older adults in the US watch television on a given day, and the average viewing time is nearly $5 \mathrm{~h} /$ day, indicating that a large proportion of older adults may be at increased risk due to prolonged television viewing.

We also demonstrated that adults who increased their viewing over time had a $17-45 \%$ higher risk, and that individuals who chose to reduce their viewing time had an $12-15 \%$ lower mortality, compared to those who maintained the same viewing patterns over time. In the only mortality studies of which we are aware to examine changes in sedentary behavior, Leon-Munoz reported that reductions in reported sitting time from $5+$ to $<5 \mathrm{~h} /$ day over two years was associated with a nonsignificant $14 \%$ lower mortality risk (0.86 [0.70-1.05]), compared to consistently sitting $<5 \mathrm{~h} /$ day [33] and Lee et al., reported that women who reduced sitting had a $29 \%$ lower mortality risk compared to those who maintained 


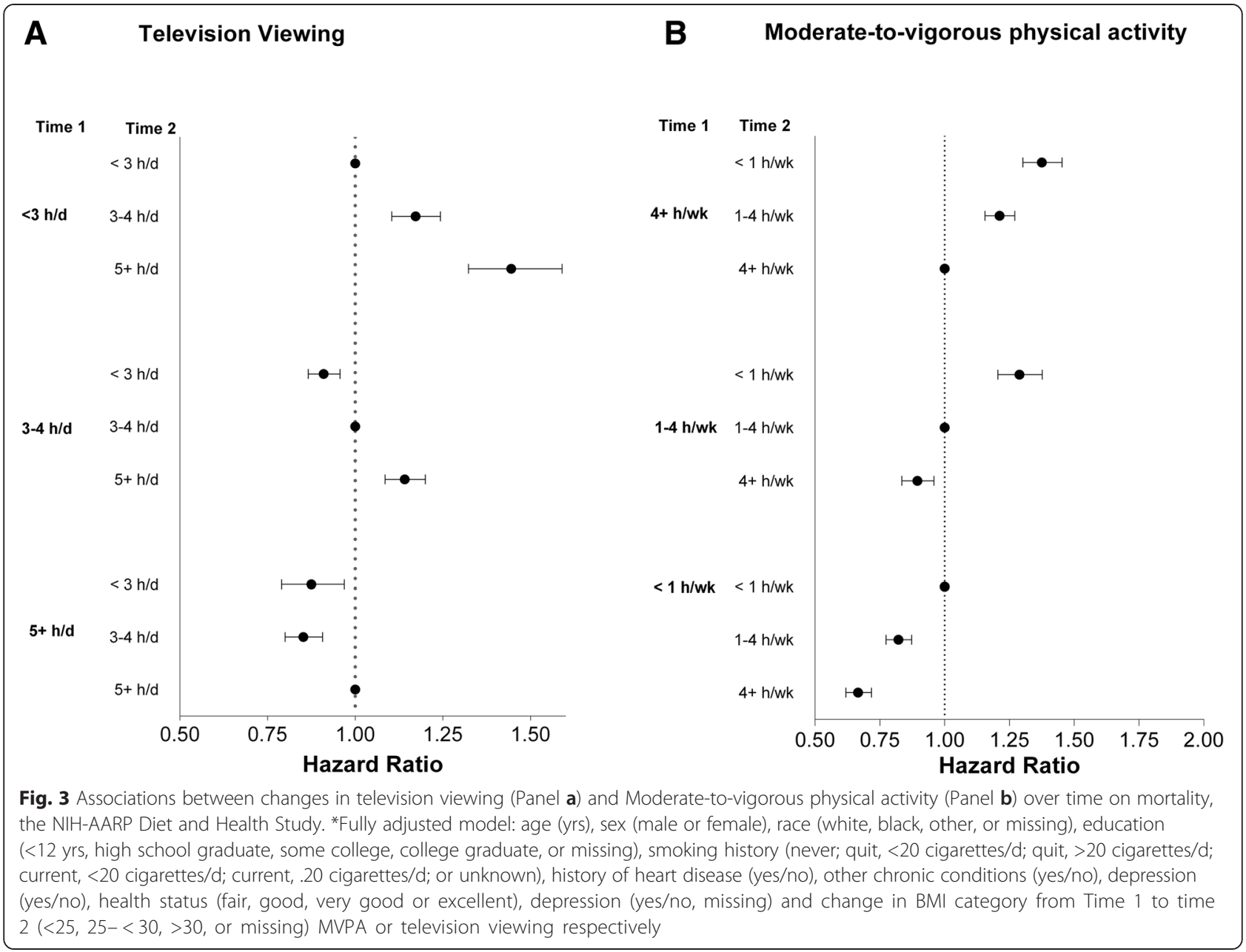

high levels of sitting [34] . Collectively, these data supports the idea that reducing sedentary behavior may have important mortality benefits and suggests that intervention strategies to reduce prolonged television viewing time could be an important behavioral approach to improve the health and longevity of older adults.

There are plausible behavioral and biological mechanisms that explain our findings. Television viewing is adversely associated with weight gain $[35,36]$, diabetes [13], glucose homeostasis [37], and other cardiometabolic risk factors [38]. In addition to the aforementioned metabolic risk factors, reductions in television viewing may also increase overall physical activity. A randomized trial found that a $2.9 \mathrm{~h} /$ day reduction in television viewing resulted in an increase in objectively measured physical activity of about $120 \mathrm{kcal} /$ day [39], which is roughly equivalent to walking one mile per day. Prolonged television viewing also has been associated with lower cardiorespiratory fitness [40] and two weeks of imposed inactivity has been found to reduce cardiorespiratory fitness even in healthy young adults [41]. Although such data are unavailable for older adults, we hypothesize that the mortality benefits associated with reduced television time may be mediated by increased physical activity [43] and possibly greater cardiorespiratory fitness, a powerful determinant of mortality [42]. Our hypothesis is that sedentary television viewing is replaced with physical activity, which provides the mortality benefits observed for those who reported reducing television viewing. Future studies are needed to understand more completely the mechanisms underlying these associations, and to define the type and intensity of physical activity that may be providing the hypothesized replacement benefit. To fully understand the mortality associations between the different components of activity (i.e., sedentary, light, moderate) better measurements, such as previous day recalls [44] or activity monitors that capture total daily activity are needed in prospective studies. Future intervention studies that include robust measures are needed to determine how to effectively reduce sedentary television viewing, increase physical activity and determine the subsequent impact on health-related outcomes. 
Table 3 Sensitivity Analyses for association between changes in television viewing and mortality: the NIH-AARP Diet and Health Study

\begin{tabular}{|c|c|c|c|c|c|c|c|c|c|c|}
\hline \multirow{2}{*}{$\begin{array}{l}\text { Time } 1 \\
\text { Time } 2\end{array}$} & \multirow[b]{2}{*}{ No. deaths } & \multicolumn{3}{|l|}{$<3$ h/day } & \multicolumn{3}{|l|}{ 3-4 h/day } & \multicolumn{3}{|l|}{$5+$ h/day } \\
\hline & & $<3 \mathrm{~h} / \mathrm{d}$ & $3-4 \mathrm{~h} / \mathrm{d}$ & $5+h / d$ & $<3 \mathrm{~h} / \mathrm{d}$ & $3-4 \mathrm{~h} / \mathrm{d}$ & $5+h / d$ & $<3 \mathrm{~h} / \mathrm{d}$ & $3-4 \mathrm{~h} / \mathrm{d}$ & $5+h / d$ \\
\hline Overall & 20,104 & 1.0 (referent) & $1.17(1.10,1.24)$ & $1.45(1.32,1.58)$ & $0.91(0.87,0.96)$ & 1.0 (referent) & $1.14(1.09,1.20)$ & $0.88(0.79,0.97)$ & $0.85(0.80,0.91)$ & 1.0 (referent) \\
\hline Men & 13,251 & 1.0 (referent) & $1.21(1.13,1.30)$ & $1.39(1.25,1.56)$ & $0.94(0.89,1.00)$ & 1.0 (referent) & $1.11(1.04,1.18)$ & $0.92(0.81,1.05)$ & $0.86(0.80,0.94)$ & 1.0 (referent) \\
\hline Women & 6853 & 1.0 (referent) & $1.09(0.98,1.21)$ & $1.54(1.32,1.79)$ & $0.84(0.77,0.92)$ & 1.0 (referent) & $1.21(1.11,1.32)$ & $0.82(0.69,0.97)$ & $0.84(0.76,0.92)$ & 1.0 (referent) \\
\hline Normal weight & 8560 & 1.0 (referent) & $1.16(1.06,1.27)$ & $1.43(1.25,1.64)$ & $0.87(0.81,0.94)$ & 1.0 (referent) & $1.17(1.08,1.26)$ & $0.86(0.74,1.01)$ & $0.86(0.77,0.95)$ & 1.0 (referent) \\
\hline Overweight/obese & 11,544 & 1.0 (referent) & $1.18(1.09,1.28)$ & $1.46(1.30,1.64)$ & $0.94(0.88,1.01)$ & 1.0 (referent) & $1.13(1.06,1.20)$ & $0.89(0.78,1.02)$ & $0.85(0.78,0.92)$ & 1.0 (referent) \\
\hline Younger & 5968 & 1.0 (referent) & $1.14(1.03,1.26)$ & $1.56(1.36,1.80)$ & $0.92(0.84,1.01)$ & 1.0 (referent) & $1.16(1.06,1.28)$ & $0.79(0.65,0.96)$ & $0.75(0.66,0.84)$ & 1.0 (referent) \\
\hline Older & 8231 & 1.0 (referent) & $1.19(1.11,1.28)$ & $1.36(1.21,1.53)$ & $0.91(0.85,0.96)$ & 1.0 (referent) & $1.13(1.07,1.20)$ & $0.91(0.81,1.03)$ & $0.89(0.83,0.96)$ & 1.0 (referent) \\
\hline$>1$ yr Follow-up & 18,506 & 1.0 (referent) & $1.17(1.10,1.24)$ & $1.44(1.31,1.58)$ & $0.91(0.86,0.95)$ & 1.0 (referent) & $1.12(1.06,1.18)$ & $0.87(0.78,0.97)$ & $0.85(0.80,0.91)$ & 1.0 (referent) \\
\hline Excluding chronic conditions & 8231 & 1.0 (referent) & $1.11(1.01,1.21)$ & $1.41(1.22,1.62)$ & $0.94(0.87,1.01)$ & 1.0 (referent) & $1.12(1.03,1.21)$ & $0.88(0.75,1.02)$ & $0.84(0.76,0.93)$ & 1.0 (referent) \\
\hline
\end{tabular}

Note: Time 1 was 1995-1996, Time 2 was 2004-2005. Chronic conditions included reported history of cardiovascular disease, cancer, renal disease or neurodegenerative conditions (Parkinson's Diease, Amyotrophic lateral sclerosis or Multiple Sclerosis). Younger individuals were below median age $(71.2 \mathrm{y}$ at Time 2$)$ and older were greater than or equal to the median age. Nomal-weight was BMI $<25 \mathrm{~kg} / \mathrm{m}^{2}$ and overweight/obese was greater than or equal to $25 \mathrm{~kg} / \mathrm{m}^{2}$

Fully adjusted model: age (yrs), sex (male or female), race (white, black, other, or missing), education (<12 yrs, high school graduate, some college, college graduate, or missing), smoking history (never; quit, <20

cigarettes/d; quit, $>20$ cigarettes/d; current, $<20$ cigarettes/d; current, .20 cigarettes/d; or unknown), history of heart disease (yes/no, missing), other chronic conditions (yes/no , missing), depression (yes/no, missing),

health status (fair, good, very good or excellent), and change in BMI category from Time 1 to Time $2(<25,25-<30,>30$, or missing) and MVPA 
Table 4 Combined effects of maintenance and changes in both television viewing and MVPA between Time 1 and Time 2, the $\mathrm{NIH}-\mathrm{AARP}$ Diet and Health Study

\begin{tabular}{|c|c|c|c|c|c|}
\hline \multirow{2}{*}{ MVPA } & & \multirow[b]{2}{*}{$\begin{array}{l}\text { Maintain high } \\
(\geq 3 \mathrm{~h} / \text { day })\end{array}$} & \multicolumn{2}{|l|}{ Television viewing } & \multirow[b]{2}{*}{$\begin{array}{l}\text { Maintain low } \\
(<3 \mathrm{~h} / \text { day })\end{array}$} \\
\hline & & & $\begin{array}{l}\text { Increased (<3 to } \\
\geq 3 \mathrm{~h} / \text { day) }\end{array}$ & $\begin{array}{l}\text { Reduced ( } \geq 3 \text { to } \\
<3 \mathrm{~h} / \text { day) }\end{array}$ & \\
\hline Maintain low (<1 h/wk) & $\begin{array}{l}\text { No. Deaths } \\
\text { Hazard ratio }(\mathrm{Cl})\end{array}$ & $\begin{array}{l}1700 \\
1.0 \text { (referent) }\end{array}$ & $\begin{array}{l}251 \\
1.03(0.90,1.17)\end{array}$ & $\begin{array}{l}330 \\
0.91(0.81,1.02)\end{array}$ & $\begin{array}{l}334 \\
0.80(0.72,0.90)\end{array}$ \\
\hline Reduced ( $\geq 1$ to $<1 \mathrm{~h} / \mathrm{wk}$ ) & $\begin{array}{l}\text { No. Deaths } \\
\text { Hazard ratio }(\mathrm{Cl})\end{array}$ & $\begin{array}{l}2257 \\
0.91(0.85,0.97)\end{array}$ & $\begin{array}{l}428 \\
1.11(1.0,1.24)\end{array}$ & $\begin{array}{l}502 \\
0.79(0.71,0.87)\end{array}$ & $\begin{array}{l}634 \\
0.83(0.76,0.91)\end{array}$ \\
\hline Increased ( $<1$ to $\geq 1 \mathrm{~h} / \mathrm{wk}$ ) & $\begin{array}{l}\text { No. Deaths } \\
\text { Hazard ratio }(\mathrm{Cl})\end{array}$ & $\begin{array}{l}1684 \\
0.77(0.72,0.82)\end{array}$ & $\begin{array}{l}283 \\
0.69(0.61,0.78)\end{array}$ & $\begin{array}{l}400 \\
0.71(0.63,0.79)\end{array}$ & $\begin{array}{l}521 \\
0.66(0.60,0.73)\end{array}$ \\
\hline Maintain high ( $\geq 1 \mathrm{~h} / \mathrm{wk}$ ) & $\begin{array}{l}\text { No. Deaths } \\
\text { Hazard ratio }(\mathrm{Cl})\end{array}$ & $\begin{array}{l}5590 \\
0.72(0.68,0.76)\end{array}$ & $\begin{array}{l}1223 \\
0.75(0.69,0.81)\end{array}$ & $\begin{array}{l}1580 \\
0.62(0.58,0.67)\end{array}$ & $\begin{array}{l}2387 \\
0.60(0.56,0.64)\end{array}$ \\
\hline
\end{tabular}

Time 1 (1995-1996), Time 2 (2004-2006). MVPA (Moderate-to-vigorous physical activity) Fully adjusted model: age (yrs), sex (male or female), race (white, black, other, or missing), education ( $<12 \mathrm{yrs,} \mathrm{high} \mathrm{school} \mathrm{graduate,} \mathrm{some} \mathrm{college,} \mathrm{college} \mathrm{graduate,} \mathrm{or} \mathrm{missing),} \mathrm{smoking} \mathrm{history} \mathrm{(never;} \mathrm{quit,}<20$ cigarettes/d; quit, $>20$ cigarettes/d; current, $<20$ cigarettes/d; current, .20 cigarettes/d; or unknown), history of heart disease (yes/no), depression (yes/no, missing), other chronic conditions (yes/no), health status (fair, good, very good or excellent), and change in BMl category from Time 1 to Time 2 ( $<25,25-<30,>30$, or missing)

Strengths of our report include a study design that defined the temporal sequence between changes in behavior and mortality in a large cohort enabling precise risk estimates. We also took a number of steps to address the potential for reverse causation. First, the change analysis alleviates some concerns, as this potential bias is expected to be minimal when an individual who watches a lot of television at baseline subsequently reduces their television viewing, or when an inactive individual increases MVPA. We conducted a number of sensitivity analyses by different follow-up times and excluding those reporting any chronic disease (e.g., heart disease, cancer, renal disease, and degenerative neurological conditions) and our results remained consistent (Table 3, Additional file 1: Table S5-S6). In addition, we adjusted for important potential confounders including age, demographics, smoking, BMI, and reported health status and considered many others (e.g., sleep duration and diabetes) that did not change our results. It is important to note that the change results were adjusted for change in BMI and health status, both of which could be on the causal pathway between exposure and outcome, but also could be confounders thus we elected to provide a conservative risk estimate. Due to concerns about depression causing increases in television viewing, we adjusted for depression as well and the effect estimates were virtually identical.

The limitations of our study must also be considered. Television viewing has been associated with an unhealthy diet and while we could not control for recent diet in this study, we previously reported that diet quality was not a confounder of the television mortality association $[10,17]$. We relied on self-selected maintenance or changes in behavior over time, rather than an experimental manipulation per se, therefore unmeasured residual confounding associated with these changes could have influenced our results. We do not know the types of activity that replaced sedentary television viewing for those who reported reducing this behavior. The measures of television and MVPA were both self-reported and the specific questionnaire has not been validated compared to a criterion measure. Reporting errors could introduce some bias in our results, particularly for the risk estimates for changing to an adjacent duration category. However, reporting errors are expected to attenuate the associations observed. For MVPA the recall period for the Time 1 (past 10 years) questionnaire was different than for Time 2 (past year), but our results for MVPA were similar in magnitude and direction to previous studies that have examined changes in MVPA and mortality risk among older adults [3, 4, 31] providing some reassurance that our harmonization efforts for MVPA were reasonable. Although we included those with preexisting conditions to increase both our sample-size and generalizability, our results are most applicable to older adults who are likely to live into their early 70's with similar behavioral, demographic and health characteristics.

\section{Conclusions}

In summary, our data provide further evidence that prolonged television viewing is associated with greater mortality risk and we demonstrate that older adults who chose to reduce their television viewing time had lower mortality compared to those who consistently watched more television. Collectively, our data provide clinicians and public health professionals with new evidence to support behavioral interventions designed to reduce sedentary television viewing in favor of more physically active pursuits, preferably more MVPA. Future studies are needed to confirm our findings for changes in television and mortality and experimental trials are need to better understand the behavioral and biological mechanisms that mediate the associations observed in this report. 


\section{Additional file}

\section{Additional file 1: Supplementnal Methods and Results. (DOC $692 \mathrm{~kb}$ )}

\section{Competing interests}

None reported

\section{Authors' contributions}

Dr. Keadle had full access to all of the data in the study and takes responsibility for the integrity of the data and the accuracy of the data analysis. Study concept and design: SKK, CEM. Analysis and interpretation of data: SKK, CEM, SCM, HA, JNS. Drafting of the manuscript: SKK, CEM, SCM, HA, JNS. Critical revision of the manuscript for important intellectual content: SKK, CEM, SCM, HA, JNS. Obtained funding: CEM. All authors read and approved the final manuscript.

\section{Acknowledgments}

We are indebted to the participants in the NIH-AARP Diet and Health Study for their outstanding cooperation.

\section{Funding}

This research was supported in part by the Intramural Research Program at the National Cancer Institute, National Institute of Health.

\section{Author details}

${ }^{1}$ Nutritional Epidemiology Branch, Division of Cancer Epidemiology and Genetics, National Cancer Institute, Bethesda, MD, USA. ${ }^{2}$ Cancer Prevention Fellowship Program, Division of Cancer Prevention, National Cancer Institute, Bethesda, MD, USA. ${ }^{3}$ Biostatistics Branch, Division of Cancer Epidemiology and Genetics, National Cancer Institute, Bethesda, MD, USA

Received: 11 July 2015 Accepted: 4 December 2015 Published online: 18 December 2015

\section{References}

1. Vincent GK, Velkoff VA. The Next Four Decades The Older Population in the United States: 2010 to 2050. US Department of Commerce, US Census Bureau Washington, DC 2010. p. 1125-1138. www.census.gov/prod/ 2010pubs/p25-1138.pdf.

2. Kochanek KD, Murphy SL, Xu J, Arias E. Mortality in the United States, 2013. NCHS data brief, no 178. Hyattsville, MD: National Center for Health Statistics; 2014.

3. Paffenbarger R, Hyde R, Wing A, Lee I, Jung D, Kampert J. The association of changes in physical activity level and other lifestyle characteristics with mortality among men. New Eng J Med. 1993;328(8):538-45.

4. Wannamethee SG, Shaper AG, Walker M. Changes in physical activity, mortality, and incidence of coronary heart disease in older men. Lancet. 1998:351(9116):1603-8. doi:10.1016/s0140-6736(97)12355-8.

5. Pahor M, Guralnik JM, Ambrosius WT, Blair S, Bonds DE, Church TS, et al. Effect of structured physical activity on prevention of major mobility disability in older adults: the LIFE study randomized clinical trial. JAMA. 2014;311(23):2387-96. doi:10.1001/jama.2014.5616.

6. Matthews CE, Chen KY, Freedson PS, Buchowski MS, Beech BM, Pate RR, et al. Amount of time spent in sedentary behaviors in the United States, 20032004. Am J Epidemiol. 2008:167(7):875-81. doi:10.1093/aje/kwm390.

7. Brownson RC, Boehmer TK, Luke DA. Declining rates of physical activity in the United States: What Are the Contributors? Annu Rev Public Health. 2004;26(1):421-43

8. Robinson JP, Godbey G. Trends in Television Time and Other Media. Time for Life: The Surprising Ways Americans Use Their Time. University Park: The Pennsylvania State University Press; 1997. p. 136-53.

9. Bureau of Labor and Statistics. American Time Use Survey for older adults (65y+). (Unpublished Tables) http://www.bls.gov/tus/home.htm, 2015.

10. Matthews CE, George SM, Moore SC, Bowles HR, Blair A, Park Y, et al. Amount of time spent in sedentary behaviors and cause-specific mortality in US adults. Am J Clin Nutr. 2012:95(2):437-45. doi:10.3945/ajcn.111.019620.

11. Dunstan DW, Barr ELM, Healy GN, Salmon J, Shaw JE, Balkau B, et al. Television Viewing Time and Mortality. The Australian Diabetes, Obesity and Lifestyle Study (AusDiab). Circulation. 2010;121:384-91.
12. Wijndaele K, Brage S, Besson H, Khaw KT, Sharp SJ, Luben R, et al. Television viewing time independently predicts all-cause and cardiovascular mortality: the EPIC Norfolk Study. Int J Epidemiol. 2010;40(1):150-9.

13. Grøntved A, Hu FB. Television viewing and risk of type 2 diabetes, cardiovascular disease, and all-cause mortality: A meta-analysis. JAMA. 2011; 305(23):2448-55. doi:10.1001/jama.2011.812.

14. Basterra-Gortari FJ, Bes-Rastrollo M, Gea A, Nunez-Cordoba JM, Toledo E, Martinez-Gonzalez MA. Television viewing, computer use, time driving and all-cause mortality: the SUN cohort. J Am Heart Assoc. 2014;3(3):e000864. doi:10.1161/JAHA.114.000864.

15. Ford ES. Combined television viewing and computer use and mortality from all-causes and diseases of the circulatory system among adults in the United States. BMC Public Health. 2012:12:70. doi:10.1186/1471-2458-12-70.

16. Kim Y, Wilkens LR, Park SY, Goodman MT, Monroe KR, Kolonel LN. Association between various sedentary behaviours and all-cause, cardiovascular disease and cancer mortality: the Multiethnic Cohort Study. Int J Epidemiol. 2013;42(4):1040-56. doi:10.1093/ije/dyt108.

17. Keadle SK, Moore SC, Sampson JN, Xiao Q, Albanes D, Matthews CE. Causes of Death Associated With Prolonged TV Viewing: NIH-AARP Diet and Health Study. Am J Prev Med. 2015. doi:10.1016/j.amepre.2015.05.023

18. Andersen LB. Relative risk of mortality in the physically inactive is underestimated because of real changes in exposure level during follow-up. Am J Epidemiol. 2004;160(2):189-95. doi:10.1093/aje/kwh195.

19. Schatzkin A, Subar AF, Thompson FE, Harlan LC, Tangrea J, Hollenbeck AR, et al. Design and serendipity in establishing a large cohort with wide dietary intake distributions: the National Institutes of Health-American Association of Retired Persons Diet and Health Study. Am J Epidemiol. 2001;154(12):1119-25.

20. Hill ME, Rosenwaike I. The Social Security Administration's Death Master File: The Completeness of Death Reporting at Older Ages. Soc Sec Bull. 2001;64(1):45-51

21. Rich-Edwards JW, Corsano KA, Stampfer MJ. Test of the National Death Index and Equifax Nationwide Death Search. Am J Epidemiol. 1994;140(11):1016-9

22. Gardiner PA, Clark BK, Healy GN, Eakin EG, Winkler EA, Owen N. Measuring older adults' sedentary time: reliability, validity, and responsiveness. Med Sci Sport Exerc. 2011;43(11):2127-33. doi:10.1249/MSS.0b013e31821b94f7.

23. Lynch BM, Friedenreich CM, Khandwala F, Liu A, Nicholas J, Csizmadi I. Development and testing of a past year measure of sedentary behavior: the SIT-Q. BMC Pub Health. 2014;14:899. doi:10.1186/1471-2458-14-899.

24. Van Cauwenberg J, Van Holle V, De Bourdeaudhuij I, Owen N, Deforche B. Older adults' reporting of specific sedentary behaviors: validity and reliability. BMC Pub Health. 2014;14:Artn 734. doi:10.1186/14712458-14-734.

25. Matton L, Wijndaele K, Duvigneaud N, Duquet W, Philippaerts R, Thomis M, et al. Reliability and validity of the Flemish Physical Activity Computerized Questionnaire in adults. Res Quart Exer Sport. 2007;78(4):293-306. doi:10.1080/02701367.2007.10599427.

26. Marshall AL, Miller YD, Burton NW, Brown WJ. Measuring total and domain-specific sitting: a study of reliability and validity. Med Sci Sport Exerc. 2010:42(6):1094-102. doi:10.1249/MSS.0b013e3181c5ec18.

27. Otten JJ, Littenberg B, Harvey-Berino JR. Relationship between self-report and an objective measure of television-viewing time in adults. Obesity. 2010;18(6):1273-5. doi:10.1038/oby.2009.371.

28. Chasan-Taber S, Rimm EB, Stampfer MJ, Spiegelman D, Colditz GA Giovannucci E, et al. Reproducibility and Validity of a Self-Administered Physical Activity Questionnaire for Male Health Professionals. Epidemiology. 1996;7(1):81-6

29. Wolf AM, Hunter DJ, Colditz GA, Manson JE, Stampfer MJ, Corsano KA, et al. Reproducibility and validity of a self-administered physical activity questionnaire. Int J Epidemiol. 1994;23(5):991-9.

30. Thomas L, Reyes EM. Tutorial Survival Estimation for Cox Regression Models with Time-Varying coefficients. J Stat Softw. 2014;61(Cs1):1-23.

31. Blair SN, Haskell WL. Objectively measured physical activity and mortality in older adults. JAMA. 2006;296(2):216-8. doi:10.1001/jama.296.2.216.

32. Biswas A, Oh PI, Faulkner GE, Bajaj RR, Silver MA, Mitchell MS. Sedentary Time and Its Association With Risk for Disease Incidence, Mortality, and Hospitalization in Adults (vol 162, pg 123, 2015). Ann Intern Med. 2015; 163(5):400. doi:10.7326/L15-5134.

33. Leon-Munoz LM, Martinez-Gomez D, Balboa-Castillo T, Lopez-Garcia E, Guallar-Castillon P, Rodriguez-Artalejo F. Continued sedentariness, change in 
sitting time, and mortality in older adults. Med Sci Sport Exer 2013;45(8):1501-7. doi:10.1249/MSS.0b013e3182897e87.

34. Lee J, Kuk JL, Ardern Cl. The relationship between changes in sitting time and mortality in post-menopausal US women. J Pub Health. 2015. doi:10.1093/pubmed/fdv055

35. Mitchell JA, Bottai M, Park Y, Marshall SJ, Moore SC, Matthews CE. A Prospective Study of Sedentary Behavior and Changes in the BMI Distribution. Med Sci Sport Exer. 2014. doi:10.1249/MSS.0000000000000366

36. Hu FB, Li TY, Colditz GA, Willett WC, Manson JE. Television watching and other sedentary behaviors in relation to risk of obesity and type 2 diabetes mellitus in women. JAMA. 2003;289(14):1785-91.

37. Hansen AL, Wijndaele K, Owen N, Magliano DJ, Thorp AA, Shaw JE, et al. Adverse associations of increases in television viewing time with 5-year changes in glucose homoeostasis markers: the AusDiab study. Diabetic Med. 2012;29(7):918-25. doi:10.1111/j.1464-5491.2012.03656.x.

38. Wijndaele K, Orrow G, Ekelund U, Sharp S, Brage S, Griffin S, et al. Increasing objectively measured sedentary time increases clustered cardiometabolic risk: a 6 year analysis of the ProActive study. Diabetologia. 2014;57(2):305-12. doi:10.1007/s00125-013-3102-y.

39. Otten JJ, Jones KE, Littenberg B, Harvey-Berino J. Effects of Television Viewing Reduction on Energy Intake and Expenditure in Overweight and Obese Adults A Randomized Controlled Trial. Arch Intern Med. 2009;169(22):2109-15.

40. Tucker LA, Arens PJ, Lecheminant JD, Bailey BW. Television Viewing Time and Measured Cardiorespiratory Fitness in Adult Women. Am J Health Promotion 2014. doi:10.4278/ajhp.131107-QUAN-565

41. Krogh-Madsen R, Thyfault JP, Broholm C, Mortensen OH, Olsen RH, Mounier $R$, et al. A 2-wk reduction of ambulatory activity attenuates peripheral insulin sensitivity. J Appl Phys. 2010;108(5):1034-40.

42. Blair SN, Kohl HW, Paffenbarger RS, Clark DG, Cooper KH, Gibbons LW. Physical fitness and all-cause mortality: a prospective study of healthy men and women. JAMA. 1989;262(17):2395-401.

43. Matthews CE, Moore SC, Sampson J, Blair A, Xiao Q, Keadle SK, et al. Mortality Benefits for Replacing Sitting Time with Different Physical Activities. MedSci Sport Exer. 2015;47(9):1833-40. doi:10.1249/MSS. 0000000000000621.

44. Matthews CE, Moore SC, Sampson J, Blair A, Xiao Q, Keadle SK et al. Mortality Benefits for Replacing Sitting Time with Different Physical Activities. Med Sci Sport Exer. 2015. doi:10.1249/mss.0000000000000621

\section{Submit your next manuscript to BioMed Central and we will help you at every step:}

- We accept pre-submission inquiries

- Our selector tool helps you to find the most relevant journal

- We provide round the clock customer support

- Convenient online submission

- Thorough peer review

- Inclusion in PubMed and all major indexing services

- Maximum visibility for your research 